\title{
Effect of Combined Acupuncture Anesthesia on Surgical Dosage and Serum IL-4, IL-10 of Pneumonectomy Patients
}

\author{
Duowen Xie1, Xiaoyuan Shi2 and Yinxia Zhang ${ }^{3}$
}

\begin{abstract}
Objective: To analyse the effects of combined acupuncture anesthesia on surgical dosage and serum interleukin-4 (IL-4), interleukin-10 (IL-10) of pneumonectomy patients.

Study Design: A randomised controlled trial (RCT).

Place and Duration of Study: Lanzhou University Second Hospital, Lanzhou, China, from January 2016 to November 2017.

Methodology: A total of 110 patients undergoing pneumonectomy were randomly divided into group $A$ and group $B$, with 55 cases in each group. Group A was treated with combined $2 \mathrm{~Hz}$ acupuncture anesthesia, while group $\mathrm{B}$ was treated with combined $2 \mathrm{~Hz} / 100 \mathrm{~Hz}$ acupuncture anesthesia. The additional propofol, fentanyl dosage, and changes in heart rate and systolic blood pressure 5 min before and during extubation were compared between the two groups. The serum IL- 4 and IL-10 levels were measured 10 minutes after skin incision and 24 hours after surgery using ELISA. Pain was rated by visual analogue scale (VAS) at 24 hours after surgery.

Results: There was no statistically significant difference between group $A$ and group $B$ in the intraoperative additional propofol and fentanyl dosags $(p=0.541$ and 0.719 , respectively). There is no statistical difference in heart rate and systolic blood pressure between group $A$ and group $B$ at 5 minutes before and during extubation $(p=0.151,0.660$ and $0.734,0.528$, respectively). There is no statistical difference between group A and group B in serum IL-4 and IL-10 levels 10 minutes after surgical incision ( $p=0.916$ and 0.841 , respectively). However, serum IL-4 and IL-2 levels in group A are statistically lower than that of group B at 24 hours after surgery (all $p<0.001$ ). The VAS score at 24 hours after surgery in group A was $2.44 \pm 0.71$ points, which was significantly lower than that of group B $(3.82 \pm 0.77$ points, $p<0.001)$.

Conclusion: Combined $2 \mathrm{~Hz}, 2 \mathrm{~Hz} / 100 \mathrm{~Hz}$ acupuncture anesthesia need few anesthetic dosages of propofol and fentanyl to stabilise the patient's blood pressure and heart rate when intubated under general anesthesia; but combined $2 \mathrm{~Hz}$ acupuncture anesthesia can reduce IL-4 and IL-10 levels during surgery stress to a greater extent than the latter, and can effectively lower patients' serum IL-4, IL-10 expression after surgery.
\end{abstract}

Key Words: Combined acupuncture anesthesia, Pneumonectomy, Propofol, Fentanyl, Interleukin-4, Interleukin-10.

\section{INTRODUCTION}

Combined acupuncture anesthesia represents an important recent achievement in Chinese acupuncture field. It cannot only reduce drug toxicity, but also compensate for the deficiency of acupuncture effect. ${ }^{1}$ During combined acupuncture anesthesia, clinical anesthesiologists can select acupoint along channel based on the patient's actual condition and provide acupuncture anesthesia by syndrome differentiation to reduce patients' pain. Studies have shown that combined acupuncture anesthesia can effectively ease pain, promote postoperative recovery of lung cancer patients, and improve the body's immune function. ${ }^{2}$

At present, most studies are based on comparative analysis of combined acupuncture anesthesia and

1 Department of Intensive Care Unit / Medical Record², Lanzhou University Second Hospital, Lanzhou, 730000, China

3 Department of Health, Northwest Minzu University Hospital, 730000, China

Correspondence: Dr. Yinxia Zhang, Department of Health, Northwest Minzu University Hospital, 730000, China E-mail:pu088u@163.com

Received: April 24, 2018; Accepted: July 12, 2018 conventional anesthetic agent anesthesia. It is confirmed that combined acupuncture anesthesia is superior to conventional drug anesthesia in terms of analgesia, reduced multiple physiological disturbances during perioperative period. 3,4 However, there are few studies on the effect of combined acupuncture anesthesia under electroacupuncture stimulation of different frequencies on perioperative inflammatory factors of pneumonectomy patients.

Serum interleukin-4 (IL-4) and interleukin-10 (IL-10) are common clinical serum inflammatory cytokines that are involved in the incidence and development of lung cancer diseases, etc. 5, 6

This study aimed to investigate the effects of combined acupuncture anesthesia under electroacupuncture stimulation of different frequencies on anesthetic dosage and serum IL-4 and IL-10 inflammatory cytokines of pneumonectomy patients. It is hoped that reference will be provided for surgical anesthesia in pneumonectomy patients.

\section{METHODOLOGY}

This study was conducted at Lanzhou University Second Hospital, Lanzhou, China, from January 2016 to 
November 2017. A total of 110 patients undergoing pneumonectomy from January 2016 to November 2017 in the hospital were selected as subjects.

Inclusion criteria were meeting the indications for pneumonectomy and receiving acupuncture anaesthesia treatment for the first time, falling in levels I-II grade by American Anesthesiologists Association (ASA), without prior immune system disease and have signed the informed consent. Exclusion criteria were patients who had undergone surgery on the meridian course of the meridian points, with skin infections on the meridian points, and who failed to complete the study plan.

The selected subjects were randomly divided into group A and group B, with 55 cases in each group. Group A was treated with combined $2 \mathrm{~Hz}$ acupuncture anesthesia. For the specific method, for bilateral acupuncture points like Neiguan, Zhigou, Houxi, Hegu, nerve Han's acupuncture point stimulator was selected for electro-acupuncture, with frequency adjusted to $2 \mathrm{~Hz}$. After acupuncture insertion, electro-acupuncture was joined at the needle handle by mild reinforcingattenuating, with current intensity adjusted based on the patient's pain degree; electro-acupuncture stimulation was maintained by venous induction 30 minutes later. For intravenous combined general anesthesia, provide intravenous infusion of $1-2 \mathrm{mg} / \mathrm{Kg}$ propofol during general anesthesia which was intraoperatively maintained at 3-6 mg/Kg/h, intravenous infusion of 5 $\mathrm{ug} / \mathrm{Kg}$ fentanyl which was intraoperatively maintained at $2-5 \mathrm{ug} / \mathrm{Kg} / \mathrm{hour}$, intravenous infusion of $0.05 \mathrm{mg} / \mathrm{Kg}$ midazolam, $0.1 \mathrm{mg} / \mathrm{Kg}$ vecuronium bromide which was maintained intraoperatively at $0.05 \mathrm{mg} / \mathrm{Kg} / \mathrm{h}$. The speed was maintained at the level set by the infusion pump until the surgery ends. Group B was treated with

Table I: Comparison of additional propofol and fentanyl dosages in the two groups.

\begin{tabular}{l|c|cc|cc}
\hline Groups & $\mathrm{n}$ & \multicolumn{2}{|c|}{ Propofol $(\mathrm{mg} / \mathrm{kg})$} & \multicolumn{2}{c}{ Fentanyl $(\mathrm{mg} / \mathrm{kg})$} \\
\cline { 3 - 6 } & & Mean $\pm \mathrm{SD}$ & $\mathrm{p}$-value & Mean $\pm \mathrm{SD}$ & $\mathrm{p}$-value \\
\hline Group A & 55 & $3.34 \pm 0.51$ & 0.541 & $1.86 \pm 0.56$ & 0.719 \\
Group B & 55 & $3.28 \pm 0.52$ & & $1.90 \pm 0.53$ & \\
\hline
\end{tabular}

combined $2 \mathrm{~Hz} / 100 \mathrm{~Hz}$ acupuncture anesthesia. Han's acupoint stimulator was alternately applied at frequencies of $2 \mathrm{~Hz}$ and $100 \mathrm{~Hz}$. Other combined acupuncture anesthesia procedures and venous combined general anesthesia methods were the same as in group $A$.

Additional propofol, and fentanyl dosage was compared between the two groups. Changes in heart rate and systolic blood pressure five minutes before and during extubation were also compared. Serum IL-4 and IL-10 levels were measured 10 minutes after skin incision and 24 hours after surgery using enzyme linked immunosorbent assay - sandwich technique (ELISA). The pain of the two groups at 24 hours after surgery was rated by visual analogue scale (VAS).

The data was analysed using SPSS 21.0 software. The measurement data was expressed as $\chi \pm s$. Independent sample t-test was used for comparison between groups. $\mathrm{P}<0.05$ indicates statistically significant difference.

\section{RESULTS}

There were 61 males (55.45\%) and 49 females (44.55\%), aged $40-65$ years, with an average age of $55.27 \pm 2.16$ years. There was no statistical difference between group $A$ and group $B$ in the intraoperative additional propofol and fentanyl dosags $(p=0.541$ and 0.719 respectively, Table I). Similarly, there was no statistical difference in heart rate and systolic blood pressure between group $A$ and group $B$ at 5 min before and during extubation $(p=0.151,0.660$ and $0.734,0.528$, respectively, Table II). There was no statistically significant difference between group $A$ and group $B$ in serum IL-4 and IL-10 levels at 10 minutes after surgical incision ( $p=0.916$ and 0.841 , respectively). However, serum IL-4 and IL-2 levels in group A are statistically lower than that of group B at 24 hours after surgery (all $\mathrm{p}<0.001$, Table III).

The VAS score at 24 hours after surgery in group A was a $2.44 \pm 0.71$ points, which was significantly lower than that of group $B(3.82 \pm 0.77$ points, $p<0.001)$.

Table II: Comparison of heart rate and systolic blood pressure in the two groups.

\begin{tabular}{|c|c|c|c|c|c|c|c|c|c|}
\hline \multirow[t]{2}{*}{ Groups } & \multirow[t]{2}{*}{$\mathrm{n}$} & \multicolumn{2}{|c|}{$\begin{array}{l}\text { Heart rate at } 5 \mathrm{~min} \\
\text { before extubation } \\
\text { (frequency/min) }\end{array}$} & \multicolumn{2}{|c|}{$\begin{array}{l}\text { Heart rate during } \\
\text { extubation } \\
\text { (frequency/min) }\end{array}$} & \multicolumn{2}{|c|}{$\begin{array}{l}\text { Systolic blood pressure } \\
\text { at } 5 \mathrm{~min} \text { before extubation } \\
(\mathrm{mmHg})\end{array}$} & \multicolumn{2}{|c|}{$\begin{array}{l}\text { Systolic blood pressure } \\
\text { during extubation } \\
(\mathrm{mmHg})\end{array}$} \\
\hline & & Mean $\pm S D$ & $p$-value & Mean $\pm S D$ & $p$-value & Mean $\pm S D$ & $p$-value & Mean \pm SD & $p$-value \\
\hline Group A & 55 & $71.28 \pm 2.58$ & 0.151 & $85.16 \pm 4.58$ & 0.660 & $121.74 \pm 9.04$ & 0.734 & $134.65 \pm 6.02$ & 0.528 \\
\hline Group B & 55 & $72.12 \pm 3.44$ & & $84.71 \pm 6.02$ & & $122.51 \pm 14.14$ & & $133.84 \pm 7.32$ & \\
\hline
\end{tabular}

Table III: Comparison of serum IL-4 and IL-10 levels in the two groups.

\begin{tabular}{|c|c|c|c|c|c|c|c|c|c|}
\hline \multirow[t]{2}{*}{ Groups } & \multirow[t]{2}{*}{$\mathrm{n}$} & \multicolumn{2}{|c|}{$\begin{array}{l}\mathrm{IL}-4 \text { at } 10 \text { minutes } \\
\text { after surgical incision } \\
(\mathrm{ng} / \mathrm{L})\end{array}$} & \multicolumn{2}{|c|}{$\begin{array}{l}\mathrm{IL}-4 \text { at } 24 \text { hours } \\
\text { after surgery } \\
(\mathrm{ng} / \mathrm{L})\end{array}$} & \multicolumn{2}{|c|}{$\begin{array}{l}\mathrm{IL}-10 \text { at } 10 \text { minutes } \\
\text { after surgical incision } \\
(\mathrm{ng} / \mathrm{L})\end{array}$} & \multicolumn{2}{|c|}{$\begin{array}{l}\mathrm{IL}-10 \text { at } 24 \text { hours } \\
\text { after surgery } \\
(\mathrm{ng} / \mathrm{L})\end{array}$} \\
\hline & & Mean $\pm S D$ & $p$-value & Mean $\pm S D$ & $p$-value & Mean $\pm S D$ & $\mathrm{p}$-value & Mean $\pm S D$ & $p$-value \\
\hline Group A & 55 & $27.74 \pm 3.01$ & 0.916 & $27.48 \pm 5.16$ & $<0.001$ & $45.95 \pm 2.15$ & 0.841 & $45.24 \pm 3.44$ & $<0.001$ \\
\hline Group B & 55 & $27.81 \pm 3.87$ & & $34.36 \pm 6.02$ & & $45.83 \pm 3.87$ & & $56.35 \pm 5.59$ & \\
\hline
\end{tabular}




\section{DISCUSSION}

The acupoints selected for the combined acupuncture anesthesia in this study included Neiguan, Zhigou, Houxi and Hegu. Among them, Neiguan is pericardium meridian point that can quiet the heart and soothe the nerves; Zhigou is triple energizer meridian point internally-externally related to pericardium channel, which can boost triple energizer vitality, promote blood circulation and ease pain by compatibility with Neiguan. The incision for pneumonectomy is usually located in the rib of affected side, so this point is commonly used. Houxi is small intestine meridian stream point connected to the governor meridian, which can adjust yang channel qi of the body and prevent invasion of exogenous pathogenic factors. ${ }^{7}$ Hegu is large intestine meridian source point internally-externally related to lung channel, which can relieve convulsion, pain, quiet the heart and soothe the nerves. Combined use of above acuepoints can both ease pain and reduce cardiovascular stress. ${ }^{8}$

In clinical general anesthesia, propofol is often used for sedation, and fentanyl is used for analgesia. The combination of propofol and fentanyl improves analgesia and sedation effects. ${ }^{9}$ Relevant studies have shown that acupuncture at Hegu and Neiguan acupoints can increase the analgesic effect of anesthesia, and reduce intraoperative dosages of propofol and fentanyl compared with conventional drug anesthesia. 10 However, there are few studies on the effect of combined acupuncture anesthesia under electroacupuncture stimulation of different frequencies on anesthetic agent dosages of pneumonectomy patients. This study showed no statistical difference between group $A$ and group $B$ in intraoperative additional propofol and fentanyl. It indicates that combined $2 \mathrm{~Hz}, 2 \mathrm{~Hz} / 100 \mathrm{~Hz}$ acupuncture anesthesia will not increase propofol, fentanyl dosages, and the anesthetic dosage is small. It suggests that electro-acupuncture stimulation under frequency of $2 \mathrm{~Hz}, 2 \mathrm{~Hz} / 100 \mathrm{~Hz}$ can receive long-lasting analgesic effect, which provides a certain reference for clinical selection of electroacupuncture frequency parameters.

Studies have shown that acupuncture can produce a certain effect on the body's autonomic nerves through advanced central integration, thus achieving bidirectional adjustment of arrhythmia. ${ }^{11}$ This study showed no statistical difference between group $A$ and group B in heart rate and systolic blood pressure at 5 minutes before and during extubation. It indicates that stimulation of the combined $2 \mathrm{~Hz}, 2 \mathrm{~Hz} / 100 \mathrm{~Hz}$ electroacupuncture frequency during general anesthesia can stabilise the blood pressure and heart rate when the patient is intubated under general anesthesia induction. The reasons may be multiple. Acupuncture signals can be transmitted to the cardiovascular reflex center via acupoints, and play a regulatory role in this part. The smooth transmission of acupuncture signals to the central axis can inhibit the sympathetic nerve activity, thereby reducing stress response. Acupuncture signal can inhibit renin-angiotensin-aldosterone system to promote the body's blood pressure and heart rate stability. 12,13

Cytokines can reflect the stress degree of surgery to a certain extent. It has many biological effects, such as regulating the body's immune function, participating in the incidence of inflammatory reactions. ${ }^{14} \mathrm{IL}-4$ and IL-10 are common cytokines which are considered as important inflammatory markers for the body's stress response process. ${ }^{15-17}$ This study showed no statistical difference between group A and group B in IL-4 and IL-10 levels at 10 minutes after skin incision. However, the authors observed in the experiment that IL-4 and IL-10 levels increased significantly at 24 hours after surgery compared with those 24 hours before surgery, indicating that both groups developed stress response after surgery; but compared with that at 10 minutes after skin incision, IL-4 and IL-10 levels increased significantly in group $B$ at 24 hours after surgery, while no significant change was observed in group $A$, indicating that group $A$ was able to reduce IL-4, IL-10 levels during stress. There was no significant difference between group $A$ and group B in IL-4 and IL-10 levels at 10 minutes after skin incision. The IL-4 and IL-10 levels were lower in group A than group $B$ at 24 hours after surgery. It suggests that combined $2 \mathrm{~Hz}$ acupuncture anesthesia can more effectively reduce IL-4 and IL-10 levels during stress, and can better regulate IL-4 and IL-10 expression in human serum, thereby promoting the perioperative environmental balance of pneumonectomy patients.

Further analysis found that the VAS score was significantly lower in group A than group B at 24 hours after surgery. It indicates that combined $2 \mathrm{~Hz}$ acupuncture anesthesia can more effectively relieve postoperative wound pain in patients. The reason may be that the analgesic effect concerns intensity, frequency, and acupoint stimulation of electroacupuncture stimulator. ${ }^{18-20}$ In this study, the same point acupuncture was selected for group $A$ and group $B$, but the frequency of stimulators used in group $A$ was $2 \mathrm{~Hz}$. Small-frequency stimulation can effectively promote the release of enkephalin and DYN in the central nervous system, which regulates pain sensation and achieves analgesic effect.21 Due to limitations in external environment, study time, number of study samples, etc., further clinical study is needed in the future as to the effect of combined electroacupuncture anesthesia on lung function indicators of pneumonectomy patients.

\section{CONCLUSION}

Combined $2 \mathrm{~Hz}, 2 \mathrm{~Hz} / 100 \mathrm{~Hz}$ acupuncture anesthesia need few anesthetic dosages of propofol and fentanyl to 
stabilise the patient's blood pressure and heart rate when intubated under general anesthesia; but combined $2 \mathrm{~Hz}$ acupuncture anesthesia can better reduce IL-4 and IL-10 levels during surgery stress than the latter, and can effectively lower patients' serum IL-4, IL-10 expression after surgery.

\section{REFERENCES}

1. Fan WC, Ma W, Zhao C, Tong QY, Shen WD. Influence of acupuncture-drug compound anesthesia with different frequency electroacupuncture on immune function in patients undergoing pneumonectomy. Zhongguo Zhen Jiu 2012; 32: 715-9.

2. Min Y, Zhu Y, Zhou H, Shi L. Clinical research of lung resection surgery with microinjection acupuncture and drug anesthesia instead of traditional acupuncture anesthesia]. Zhongguo Zhen Jiu 2015; 35:367-71.

3. Vijayalakshmi I, Shankar N, Saxena A, Bhatia MS. Comparison of effectiveness of acupuncture therapy and conventional drug therapy on psychological profile of migraine patients. Indian $\mathrm{J}$ Physiol Pharmacol 2014; 58:69-76.

4. Yang QG, Hang YN, Sun DJ. Effect of combined drugacupuncture anesthesia on hypothalamo-pituitary-adrenocortical axis response and glucose metabolism in open-heart surgery patients. Chin J Integr Tradit West Med 2001; 21:729-31.

5. Sharma S, Stolina M, Lin Y, Gardner B, Miller PW, Kronenberg M, et al. T cell-derived IL-10 promotes lung cancer growth by suppressing both t cell and apc function. J Immunol 1999; 163: 5020-8.

6. Gomes M, Coelho A, Araújo A, Teixeira AL, Catarino R, Medeiros R. Influence of functional genetic polymorphism $(-590 \mathrm{C} / \mathrm{T})$ in non-small cell lung cancer (NSCLC) development: the paradoxal role of IL-4. Gene 2012; 504:111-5.

7. Peng LC, Jiang $K Q, W u$ GL, Ding QY, Qu JH, Jin LY. Mechanism of acupuncture anesthesia for analgesia of the operative region of thyroid gland. Zhongguo Zhen Jiu 2008; 28:910-2.

8. Wang N, Ou Y, Qing W. Combined acupuncture and general anesthesia on immune and cognitive function in elderly patients following subtotal gastrectomy for gastric cancer. Oncol Lett 2018; 15:189-94.

9. Abeles G, Sequeira M, Swensen RD, Bisaccia E, Scarborough DA. The combined use of propofol and fentanyl for outpatient intravenous conscious sedation. Dermatol Surg 1999; 25: $559-62$.
10. Fu GQ, Zhou J, Tong QY, Zhu YM, Ma W, Zhou H, et al. Observation on the anti-stress effect of acupuncture-assisted anesthesia for puhnlmonary lobectomy patients. Zhen Ci Yan Jiu 2011; 36:361-5.

11. Agelink MW, Sanner D, Eich H, Pach J, Bertling R, Lemmer W, et al. Does acupuncture influence the cardiac autonomic nervous system in patients with minor depression or anxiety disorders? Fortschr Neurol Psychiatr 2003; 71:141-9.

12. Liu L Y. A new type of signaling pathways as pilomotor lines along skin for transmitting acupuncture signals to produce acupuncture effects. Chin J Physiol 2015; 58:165-77.

13. Széchenyi I, Antal Z, Hegyi G. Tracking and evaluating the immediate stress-reducing effect of ear acupuncture through prolactin levels and meridian diagnostics: a randomized, double-blinded, controlled study. Med Acupunct 2015; 27:23-32.

14. Ramanathan JM, Lee WK, Spannhake EW, Lane AP. Th2 cytokines associated with chronic rhinosinusitis with polyps down-regulate the antimicrobial immune function of human sinonasal epithelial cells. Am J Rhinol 2008; 22:115-21.

15. Sharma A, Satyam A, Sharma JB. Leptin, IL-10 and Inflammatory markers (TNF- $\alpha, \mathrm{IL}-6$ and IL-8) in pre-eclamptic, normotensive pregnant and healthy non-pregnant women. Am J Reproduc Immunol 2007; 58:21-30.

16. Glocker EO, Kotlarz D, Boztug K, Gertz EM, Schäffer AA, Noyan $\mathrm{F}$, et al. Inflammatory bowel disease and mutations affecting the interleukin-10 receptor. N Engl J Med 2009; 361: 2033-45.

17. Ding C, Parameswaran V, Udayan R, Burgess J, Jones G. Circulating levels of inflammatory markers predict change in bone mineral density and resorption in older adults: a longitudinal study. J Clin Endocrinol Metab 2008; 93:1952-8.

18. Wang Y, Wang S. Analgesic effects of electroacupuncture stimulation at different intensities and frequencies. Zhen $\mathrm{Ci}$ Yan Jiu 1993; 18:44-7.

19. Romita VV, Suk A, Henry JL. Parametric studies on electroacupuncture-like stimulation in a rat model: effects of intensity, frequency, and duration of stimulation on evoked antinociception. Brain Res Bull 1997; 42:289-96.

20. Kim SB, Choi WH, Liu WX, Lee NR, Shin TM, Lee YH. Use of pupil size to determine the effect of electromagnetic acupuncture on activation level of the autonomic nervous system. J Acupunct Meridian Stud 2014; 7:122-32.

21. Hamza MA, White PF, Ahmed HE, Ghoname EA. Effect of the frequency of transcutaneous electrical nerve stimulation on the postoperative opioid analgesic requirement and recovery profile. Anesthesiology 1999; 91:1232-8. 